\title{
TRADUCCIÓN DE TÍTULOS CIENTÍFICOS ALTAMENTE ESPECIALIZADOS: HACIA UN ESTADO DE LA CUESTIÓN
}

\section{TRANSLATION OF HIGHLY ADVANCED SCIENTIFIC TITLES: TOWARDS A STATE OF THE ART}

\author{
Viviana Soler $^{* * *}$
}

\section{RESUMEN}

El propósito de este trabajo que se realiza en el marco del proyecto de investigación "Aspectos de la textualización de los saberes científicos" (PGI 24/I205), es reflexionar sobre la traducción de títulos científicos altamente especializados. Los dos ejes sobre los que se centrarán nuestras reflexiones son: 1) la toma de decisión de si se deben traducir o no los títulos científicos altamente especializados en función del "encargo de la traducción" y de la lengua a la que se debe traducir, y 2) la precisión y corrección como condiciones claves para garantizar el cumplimiento de las funciones de los títulos en la lengua de partida y en la lengua de llegada. Estas reflexiones contribuirán a determinar cuál es el estado de la cuestión en el tema que nos ocupa, y así construir las bases de la investigación básica y aplicada que ayudarán a traducir este tipo de títulos.

Palabras claves: Discurso Científico Altamente Especializado; Traducción Científica, Títulos Científicos Altamente Especializados; Lengua Inglesa; Lengua Española.

\section{ABSTRACT}

The purpose of this paper is to reflect on issues related to the translation of highly advanced scientific titles, the latter being a topic not studied with rigor as it is the case of scientific translation in general. Our discussion will be based on two main points, namely one extrinsic to translation and another one intrinsic to translation. The former deals with decisionmakings on whether or not to translate highly advanced scientific titles depending on the "translation assignment" and on the source language. The latter deals with the principles of accuracy and correctness to guarantee that title functions are successfully achieved both in

\footnotetext{
Instituto de Investigaciones Bioquímicas de Bahía Blanca (INIBIBB), Consejo Nacional de Investigaciones Científicas y Técnicas (CONICET) - Universidad Nacional del Sur (UNS), Argentina.insoler@inibibb-conicet.gob.ar

** Expreso mi agradecimiento a la Dra. Patricia Vallejos por sus valiosos comentarios y guía durante el desarrollo del presente trabajo. Este estudio se ha realizado en el marco del proyecto "Aspectos de la Textualización de los Saberes Científicos" (PGI 24/I205 de la Secretaría de Ciencia y Técnica de la Universidad Nacional del Sur, Argentina) que dirige la Dra. P. Vallejos en el Departamento de Humanidades de la Universidad Nacional del Sur, Argentina.
} 
the source language and the target language. Our reflections will contribute to determining the state-of-the-art status on the translation of this type of titles which will further help delineate the bases of basic and applied research in the field..

Keywords: Scientific Discourse Analysis; Scientific Translation; Highly Advanced Scientific Titles; English Language; Spanish Language.

\section{INTRODUCCIÓN}

Interesante, si no difícil, será para el traductor el desafío de traducir al español títulos como, por ejemplo, los que se detallan:

- The extraction riddle: just what are we missing? En: Journal of Linguistics, 37:145-174, 2001.

- Is the emperor wearing clothes? Clinical trials of vitamin E and the LDL oxidation bypothesis. En: Arteriosclerosis, Thrombosis and Vascular Biology, 21:1261-1264, 2001.

- Oxysterols: Friends, Foes, or Just Fellow Passengers? En: Arteriosclerosis, Thrombosis and Vascular Biology, 22:734-742, 2002.

- To be or not to be (a receptor). En: Steroids, 72:107-110, 2007.

- Prevalence and prognostic value of perfusion defects detected by stress technetium-99m sestamibi myocardial perfusion single-photon emission computed tomography in asymptomatic patients with diabetes mellitus and no known coronary artery disease. En: American Journal of Cardiology, 90:827-832, 2002.

$\mathrm{Al}$ intentar resolver este desafío, seguramente surgirán aproximaciones que no solo no dejarán satisfecho al traductor y menos aún, al lector potencial, sino que llevarán a pensar en los siguientes términos:

Leyendo un título traducido de otra lengua nos preguntamos a veces por qué parece 'funcionar' tan bien aunque aparentemente no tiene nada que ver con el título original $-\mathrm{O}$ al revés-: ¿por qué el título traducido 'no suena' aunque reproduzca fielmente las palabras del título original? ¿Cuáles serán pues los criterios que rigen -o deberían regir- la traducción de un título? (Nord, 1990, p. 153)

Nord (1990) destaca que los títulos presentan un problema de traducción muy interesante que merece ser investigado no solo por razones prácticas sino por razones translatológicas ya que son verdaderos paradigmas de una traducción funcional. Particularmente en ciencia, campo que nos interesa, los títulos cumplen con todos los principios que garantizan hacer posible un ejercicio de traducción funcional: el principio de autenticidad, el principio de comunicatividad y el principio 
de transparencia. ¿En qué sentido estos principios guardan relación con el tema que nos interesa? En el sentido de que los títulos científicos son material auténtico (principio de autenticidad), se presentan en una situación comunicativa concreta (principio de comunicatividad) y permiten -en general, con alto porcentaje de precisión- determinar las condiciones de funcionamiento del título traducido (esto es, la función comunicativa que persigue el texto, los destinatarios, el motivo por el cual se produce el texto, y el medio por el cual se transmite el texto en la lengua de llegada). Por tanto, independientemente de que se deban traducir o no, los títulos científicos son excelentes ejemplares para programar y llevar a la práctica una didáctica de la traducción.

En ciencia, el título de un trabajo es la unidad textual que intenta cumplir diferentes objetivos, entre ellos: representar a dicho trabajo, diferenciarlo de otros, promocionarlo, integrar características funcionales que tienen que ver con la intención del autor y del lector, describir sintéticamente el objeto de estudio o presentarlo en forma velada, etc. La categoría de «muy especializado» es un rasgo distintivo del tipo de discurso al cual pertenecen los títulos que vamos a considerar. Es decir, los títulos científicos altamente especializados pertenecen a un discurso horizontal porque tanto su emisor/autor como su receptor/lector son pares, paridad que se manifiesta en términos del conocimiento que ambos tienen sobre un mismo objeto de estudio. Esta categoría es también un rasgo distintivo porque permite diferenciar a los títulos sobre los que se centrará nuestro trabajo de aquellos que pertenecen a otros géneros y registros del discurso científico, como es el caso del discurso de divulgación científica y del discurso de la didáctica de las ciencias en los que la relación emisor/receptor deja de ser horizontal para pasar a ser vertical. En esa verticalidad, el emisor es la autoridad en términos de conocimientos sobre un determinado objeto de estudio y desde ese nivel de «superioridad» codifica información por medio de estrategias lingüísticas y registros que no son los que corresponden a una relación de paridad, sino a una relación de desigualdad. Esta aclaración tiene por finalidad mostrar sintéticamente sobre qué tipo de títulos científicos se centrarán nuestras consideraciones.

Con respecto a la evolución que ha evidenciado la investigación sobre títulos científicos, desde que Swales (1990) a la fecha señalara que el título era una cuestión no estudiada con el rigor con el que habían sido investigadas otras partes del artículo científico, los estudios sobre títulos científicos no solo se han incrementado sino que también han revertido la observación que Swales hiciera oportunamente. Un hecho importante que confirma esta evolución es el surgimiento de lo que Baicchi (2009) acuñara con el nombre de titleology [titulología], designación que se refiere 
al estudio de títulos y que ha abarcado diferentes campos, entre ellos, el de los estudios de títulos científicos altamente especializados. Las investigaciones en este terreno son numerosas y heterogéneas (Baicchi, 2003; Fortanet, Coll García, Palmer Silveira \& Posteguillo, 1997; Fortanet Gomez, Posteguillo Gomez, Coll García \& Palmer Silveira, 1998; Goodman, Thacker \& Siegel, 2001, entre otras) y han contribuido, por ejemplo, a dilucidar cuestiones pragmáticas que revelan los títulos de determinadas disciplinas (Haggan, 2004), a identificar características indicativas de género (Hamp-Lyons, 1987; Yakhontova, 2002; Soler, 2011) y representativas desde el punto de vista disciplinar (Buxton \& Meadows, 1977; Gesuato, 2008; Laurence, 2001; Soler, 2007a), y a determinar aplicaciones que resuelven dificultades relacionadas con la lectura y redacción apropiadas de títulos científicos altamente especializados (Soler, 2011b).

Con la finalidad de complementar los estudios realizados hasta ahora, el propósito de este trabajo es realizar una exploración preliminar sobre la traducción del inglés al español y viceversa de títulos científicos altamente especializados en países de habla hispana, particularmente en América del Sur, poniendo particular atención en las características y problemas que este tipo de traducción presenta en dicho contexto geográfico. Ante la ausencia de antecedentes de estudios previos sobre el tema elegido en América del Sur, es necesario insistir en la naturaleza preliminar de este trabajo que se apoyará, por tanto, en una metodología únicamente descriptiva e informativa sobre la traducción en este campo.

Con respecto a los motivos de nuestra elección temática, estos son principalmente dos. Uno de ellos responde a la necesidad de dar continuidad a los estudios llevados a cabo hasta ahora sobre este tipo de títulos redactados en inglés y en español (Soler, 2007, 2009, 2011a,b). El otro motivo tiene que ver con la falta de consenso con respecto a la necesidad o no de contar con modelos de traducción de títulos científicos muy especializados que deriven de la aplicación y seguimiento de procedimientos lingüísticos experimentales o estratégicos para garantizar traducciones óptimas en términos de diferentes variables, por ejemplo, de género, de disciplina, de la comunidad de discurso, etc. Sobre esta última cuestión, es importante destacar el valioso aporte de los estudios que se registran en el campo de la traducción de títulos (Nord, 1990; Moya, 1993; Navarro \& Barnes, 1996; Negro, 2010; González Ruiz, 2000, 2005; Jovanovic, 1990; Chen, 2004, entre otros). De todos modos, el número de tales estudios demuestra ser comparativamente mucho menor que el número de investigaciones específicamente centradas en la traducción científica en general, hecho que, si bien no afecta la calidad de ninguno de los estudios registrados hasta ahora, indica, particularmente 
en América del Sur, un vacío en el terreno de la investigación básica y aplicada sobre el tema que nos ocupa.

Por razones de espacio y para describir organizadamente cuestiones que, entendemos, pueden ayudar a determinar el punto de partida para el marco de referencia de las futuras investigaciones en el campo básico y aplicado, nuestras descripciones se centrarán exclusivamente en dos cuestiones, una extrínseca y otra intrínseca al proceso de traducción propiamente dicho. La primera cuestión se refiere a la disyuntiva que se le puede presentar al traductor de traducir o no traducir los títulos científicos altamente especializados. La segunda cuestión se refiere a las condiciones de precisión y corrección lingüísticas para garantizar el cumplimiento de las funciones de los títulos en la lengua de partida y en la lengua de llegada. De aquí en adelante, se tratarán estas dos cuestiones por separado.

\section{DISYUNTIVA QUE PLANTEAN LOS TÍTULOS CIENTÍFICOS ALTAMENTE ESPECIALIZADOS: ¿TRADUCIRLOS O NO TRADUCIRLOS?}

Newmark (1988) sugiere pautas a seguir para la traducción de los títulos de obras literarias, pinturas, piezas musicales y títulos de notoria longitud. También sugiere que en los casos en los que se requiera traducir una obra completa, el título debe ser lo último a traducir. En su literatura, no hemos encontrado indicaciones acerca de la traducción de títulos científicos altamente especializados, y tampoco hemos encontrado normativa al respecto en otras fuentes. Por otro lado, en nuestro área de estudio hay países que han establecido disposiciones de acuerdo con las cuales, todo documento que ingresa redactado en una lengua que no es la lengua nacional debe ir acompañado de una traducción pública a la lengua nacional. Por tanto, si dicho documento incluye títulos científicos altamente especializados, estos deben traducirse dando cumplimiento a esa normativa. Este es el caso de Chile, Uruguay y la República Argentina. De todos modos, es muy importante señalar que esta normativa en dichos países rige para determinados ámbitos, particularmente el jurídico y educativo. Queda entonces un vacío sin normativa que incluye a las traducciones científicas que no llevan el rótulo de públicas. Es precisamente en dichos vacíos, que vamos a ejemplificar más adelante, en los que se le puede presentar muchas veces al traductor la disyuntiva de traducir o no los títulos científicos altamente especializados.

En virtud de lo anterior, en los casos de normativas específicas y frente al pedido de traducir textos que contienen títulos científicos altamente especializados, 
es conveniente que el traductor tenga en cuenta las variables que constituyen el encargo de traducción, en particular: i) la lengua de partida y la lengua de llegada en estrecha relación con la lengua de la ciencia -si es que estas no son las mismas-; e ii) qué función o funciones debe cumplir la traducción que se solicita. En otros términos, la variable i) tiene que ver con el medio de comunicación, y la variable ii) tiene que ver con el producto al que se llega a través de la traducción.

Analicemos la primera variable. Es verdad generalizada que el inglés es la lengua de la ciencia, hecho que ha generado un monolingüismo tácitamente aceptado por la comunidad científica y que, sin políticas lingüísticas intervinientes, conduce a una suerte de uniformización de la comunicación según códigos lingüísticos propios de la comunidad de discurso de los científicos en general. Si bien esta uniformización ayuda a comunicar los avances de la ciencia de manera estándar, también puede generar una unificación comunicativa con la que se podría correr el riesgo de eliminar cuestiones temáticas, lingüisticas y culturales que son propias de las comunidades científicas de cada lugar. Independientemente de que esto ocurra o no, para el traductor científico este monolingüismo genera dos situaciones distintas en función de que la lengua de la ciencia y la lengua de llegada sean las mismas o no lo sean. Si lo son, la calidad de trabajo del traductor cuya lengua materna no es el inglés depende del dominio que tenga este de las convenciones y códigos de ese monolingüismo. Por tanto, tratándose de una forma estándar de comunicación científica al inglés, que es a la vez la lengua de la ciencia, alcanzar ese dominio de competencias y códigos derivará de ejercitarse en la observación y práctica intensa y disciplinada de traducción a dicha lengua de llegada bajo una buena guía y entrenamiento.

Por el contrario, si no hay coincidencia de lenguas, esto, por una lado, nos retrotrae a la segunda cuestión que anunciamos al comienzo de esta sección en relación con la función que debe cumplir el título en la lengua de partida y su traducción $\mathrm{y}$, por otro lado, elimina la situación de «monolingüismo» de la que veníamos hablando, generando un trabajo más problemático para el traductor. Por tanto, entendemos que debemos abordar esta cuestión desde el punto de vista de la lengua y desde el punto de vista de la función de la traducción, y lo vamos a ejemplificar en términos hipotéticos de una traducción del inglés al español o viceversa.

Desde el punto de vista estrictamente lingüístico, y en el caso de que la lengua de llegada sea el español, el traductor advertirá que precisamente por el «monolingüismo» que impone el inglés, faltan equivalentes técnicos en la lengua española para terminología específica de la lengua inglesa (por ejemplo, patch-clamp, 
pellet, turnover) y que los códigos y estrategias de la comunidad de discurso científico de habla inglesa no siempre coinciden con los de la comunidad de discurso científico de habla española. Este es un problema que no se restringe a los títulos científicos altamente especializados sino que abarca todo el espectro de posibilidades textuales que constituyen el discurso científico altamente especializado. De todos modos, por ser el título la puerta de ingreso al contenido de todo texto, es precisamente el sitio que debe mostrar corrección en todos los planos en un espacio de exiguas dimensiones. Sin embargo, la redacción y traducción de títulos son temas que todavía no han pasado por el rigor de la investigación básica. Por tanto, al no haber herramientas que tengan el soporte de dicha investigación, el traductor puede llegar a transferir reglas gramaticales de la lengua de partida a la lengua de llegada, hecho que muchas veces genera errores en diversos planos tales como el sintáctico (por ej., eliminación de artículos, uso incorrecto del gerundio), ortográfico (por ej., uso de «proteina» en vez de «proteína» por su semejanza con el equivalente en inglés protein), léxico (por ej., anglicismos en la adjetivación y en la posición que debe llevar la adjetivación), etc.

Por otro lado, si pensamos en términos del científico que necesita una traducción a la lengua española de un artículo científico redactado en inglés -incluido su título- porque su competencia lingüística en inglés no le permite acceder al contenido del trabajo, a dicho científico no le queda otra opción que una traducción a su lengua materna de tal artículo. Sin embargo, preferirá -con seguridad-la versión inglesa si tuviera buena competencia lingüística en dicha lengua. Llamativamente entonces, la preferencia que muestran los científicos por leer y escribir ciencia en inglés con respecto a leer y escribir ciencia en su lengua materna hace más difícil aun el trabajo del traductor científico en el sector geográfico acotado para este trabajo. Esto se debe a que el traductor se prepara en principio para traducir textos científicos de la lengua inglesa a su lengua materna en coincidencia con el consenso general según el cual, se debe traducir a la lengua materna (Macshane, 1976; Gress, 1976; Orellana, 1986; García Yebra, 2001). Sin embargo, la realidad descrita exige que el proceso sea a la inversa. Por tanto, el proceso intelectual que debe desarrollar el traductor científico es muy complejo

... porque debe traducir a una lengua que no es la propia, para una comunidad lingüística que tampoco es la propia y para revistas científicas de alto índice de impacto que exigen convenciones que tampoco le son propias precisamente por haber sido establecidas por una comunidad cuya lengua materna no es el español (Soler, 2007b, p. 93).

Lo anterior está estrechamente relacionado con el «encargo de traducción» (Nord, 2010, p. 240), concepto clave en la disyuntiva de traducir o no traducir los 
títulos científicos altamente especializados. De acuerdo con Nord, es conveniente tener en claro el objetivo traslativo, es decir «el para qué de la traducción» que a su vez ayuda a determinar si el título debe traducirse o no y, en caso afirmativo, el método de traducción a seguir. Ante el interrogante de quién le indica al traductor «el para qué» del texto en la lengua de llegada, Nord (2010, p. 239) señala que «el objetivo traslativo se define mediante un encargo de traducción, que especifica explícita o implícitamente- la situación comunicativa para la que se necesita el texto meta.» Agrega también Nord (2010, p. 240) al respecto: «si conocemos la meta será más fácil producir una traducción que cumpla exactamente con los fines deseados.» El encargo de traducción es, entonces, lo que ayuda a determinar la situación para la que se requiere una traducción, situación que incluye el receptor a quien se debe dirigir la traducción y la función que se espera que cumpla la traducción.

Veamos a través de un ejemplo cómo el encargo de traducción es determinante en la toma de decisión de traducir o no los títulos científicos altamente especializados. Un curriculum vitae es un tipo de texto que, en general, incluye títulos científicos altamente especializados y que, en América del Sur, se traduce con mucha frecuencia para los países de habla inglesa. La pregunta que surge en este caso es: ¿deben traducirse los títulos de producción científica que incluye el investigador en su curriculum vitae redactados en lengua española? La respuesta depende de «el para qué» de la traducción. Si la traducción se requiere para que los antecedentes de un científico de habla hispana sean evaluados por sus pares de habla inglesa, los títulos de artículos de investigación y de revisión no se traducen. Más aún, seguramente el traductor no tenga que traducir ningún título precisamente porque por tratarse de contenido científico altamente especializado, la mayoría de los títulos de las publicaciones del científico a evaluar van a estar redactados en la lengua de la ciencia (inglés) aun cuando la producción científica pertenezca a un investigador cuya lengua materna es el español. También es probable que los títulos de las contribuciones a congresos nacionales estén redactados en lengua inglesa en respuesta a una tendencia cada vez más instalada en los países de América del Sur de habla hispana de realizar reuniones científicas nacionales e internacionales en las que la lengua de comunicación es el inglés para facilitar el intercambio e interacción con investigadores extranjeros. Cualquiera sea el caso, en presencia de títulos científicos altamente especializados originalmente redactados en lengua española, en la República Argentina y Uruguay, por ejemplo, la tendencia tácitamente consensuada es no traducir los títulos de trabajos que se incluyen en un curriculum vitae y si se tradujesen, la traducción va incluida entre corchetes y acompaña al título original en lengua española. Los motivos que subyacen a esta 
tendencia tácitamente consensuada responden a razones que no pasan solamente por el plano lingüístico y que, por tal razón, no serán tratadas en este trabajo. De todas ellas, individualizamos una que tiene que ver otra vez con el peso que ejerce el inglés en el mundo de la ciencia. Nos referimos al hecho de que a la hora de evaluar antecedentes científicos, la comunidad científica presta atención primero a lo publicado en inglés. En efecto, las revistas científicas especializadas con alto índice de impacto están redactadas en lengua inglesa, hecho que muestra cuál es el lugar que ocupa la lengua inglesa en el campo de la ciencia con respecto a otras lenguas.

Por el contrario, si cambian las condiciones de la traducción a realizar, es decir:

a) la lengua de partida y la lengua de llegada con respecto al ejemplo anterior,

b) el receptor para quien debe hacerse la traducción, y

c) la función de la traducción,

y si la traducción se requiere para un lugar o sector en el que rigen normativas sobre los documentos que allí ingresan (Monsálvez Müller, 1973; Presidencia de la Nación, República Argentina, 2009, entre otros), los títulos científicos especializados deberán traducirse. Si bien esto que señalamos es una obviedad, merece de todos modos ser analizado precisamente para distinguir cuándo es necesario traducir un título científico y cuándo no lo es. Un ejemplo claro de la necesidad de que los títulos científicos altamente especializados sean traducidos se da en la República Argentina, particularmente en la etapa de presentación de pruebas de un proceso judicial. Si la prueba que se presentase fuese un curriculum vitae redactado en lengua inglesa, el juez requerirá la traducción de dicho documento a la lengua nacional. Si analizamos las condiciones dentro de las cuales debe hacerse dicha traducción, vemos que el receptor a quien debe ir dirigida la traducción es un juez, y que la función de la traducción es presentar la información originalmente redactada en inglés, en lengua española para asistir al juez, cuya lengua materna es el español. La información que contiene el curriculum vitae es clave para la toma de la decisión final acerca de un conflicto de naturaleza judicial. En este caso, la traducción de los títulos científicos especializados debe hacerse porque el juez no solo no es par del científico del curriculum vitae cuya traducción se requiere sino que no conoce su tema de investigación. Por tanto, este ejemplo, en el que el encargo de traducción ha cambiado con respecto al ejemplo anterior, ayuda a ver con claridad que el encargo 
de traducción es determinante en la disyuntiva de traducir o no traducir los títulos científicos altamente especializados.

Trataremos ahora la segunda cuestión anunciada en la Introducción, es decir, las condiciones de precisión y corrección para garantizar el cumplimiento de las funciones de los títulos científicos en la lengua de partida y en la lengua de llegada.

\section{CONDICIONES CLAVES PARA LA TRADUCCIÓN DE TÍTULOS CIENTÍFICOS ALTAMENTE ESPECIALIZADOS}

Nord (1990) señala que los títulos cumplen las siguientes funciones:

1) la función distintiva: da nombre al trabajo de investigación y permite diferenciarlo de otros,

2) la función metatextual: muestra al título como metatexto, es decir, el título es un texto acerca de otro texto,

3) la función descriptiva o referencial: informa sobre el contenido, género o tipo del trabajo de investigación realizado,

4) la función expresiva: muestra una evaluación,

5) la función fática: establece un primer contacto entre emisor y receptor, y

6) la función operativa: llama la atención de los posibles receptores con la expectativa de que lean el artículo del cual el título es parte.

De todas ellas, la función distintiva, metatextual y fática son obligatorias en tanto que la función descriptiva, expresiva y operativa son específicas y están presentes solo en determinados tipos de títulos.

Por otro lado, Alarcos (1977) en su estudio sobre el proceso de lectura y los títulos de periódicos, analiza las funciones de este tipo de títulos en tres momentos diferentes del proceso de lectura. Tomamos la misma selección que hace Alarcos porque sus observaciones sobre títulos de periódicos pueden transferirse a los títulos científicos altamente especializados, lo cual permite determinar en qué medida reconocer apropiadamente la función de un título contribuye a garantizar una buena traducción. Esto que parece obvio requiere un análisis más cuidadoso. Alarcos entiende que es más fácil comprender las funciones de los títulos si se sigue un patrón cronológico de tres momentos: antes, durante y después de la lectura del trabajo de investigación del cual el título forma parte. Así, antes de la lectura el título es el protagonista y cumple, según Alarcos (1977), la función denominativo- 
distintiva, referencial y expresiva, porque hasta ese momento el lector no ha entrado en contacto con el contenido del trabajo. Durante la lectura del trabajo, el título cumple una función orientadora y jerarquizadora debido a que es precisamente en esta etapa en la que el contenido del título y del artículo al cual dicho título pertenece, se confrontan. Al final de la lectura, el título vuelve a tener una función denominativa-distintiva.

Con respecto a la función denominativo-distintiva en términos de Alarcos (1977) o distintiva en términos de Nord (1990), rige para todos los títulos el principio de que estos son instrumentos que sirven para identificar y diferenciar un trabajo de investigación de los demás. No obstante, aquí surge la primera dificultad porque si un título científico debe ser único en la lengua de partida debe serlo también en la lengua de llegada. Sin embargo, el principio de la función denominativa-distintiva no siempre está presente en los títulos científicos o si lo está, cumple solamente la función denominativa sin rasgos distintivos. Consideremos estos ejemplos:

- Barrantes, F.J. (1991). Structural and functional crosstalk between acetylcholine receptor and its membrane environment.

- Barrantes, F.J. (1992). Structural and functional crosstalk between the acetylcholine receptor and its membrane environment.

- Barrantes, F.J. (1992). Structural-functional crosstalk between the nicotinic acetylcholine receptor and its membrane environment.

que han sido tomados del curriculum vitae del investigador argentino Dr. Francisco J. Barrantes (Memorias del INIBIBB, 1991-1992) y que muestran el mismo título del mismo autor para tres trabajos diferentes cuyo tema es también el mismo. Si este título aparece sin elementos extralingüísticos que salven a la función distintiva, este fenómeno podría interpretarse como un caso de «doble ausencia» de la función denominativa-distintiva porque el título no es indicativo de rasgos distintivos del tema con respecto a otros estudios y tampoco es indicativo de rasgos distintivos genéricos del trabajo. Este no es un problema de traducción. De todos modos, si se requiere la traducción de estos títulos, esa doble ausencia se va a mantener en la lengua de llegada. ¿Debe solucionar esto el traductor? Si nos apoyamos en el principio de que el traductor puede mejorar el texto de partida, esta es una oportunidad hacia esa dirección. En ese caso, el trabajo del traductor incluye también cierta investigación porque deberá buscar elementos que salven el problema de «doble ausencia». Alcano (1977) propone incluir el nombre del autor, alternativa que no prospera en los ejemplos seleccionados porque el autor 
también es el mismo. Ante este tipo de igualdad de rasgos distintivos, ayuda tener en cuenta que la audiencia a la que está dirigido el título es una comunidad de pares. Por tanto, para quienes son parte de esa comunidad, los ejemplos seleccionados sin rasgos distintivos específicos que acompañen al título, como por ejemplo, fuente en la que aparece el título, indicadores genéricos, etc., son o bien excepcionalmente un error de información o bien son títulos de la misma contribución presentada por tres vías genéricas diferentes. Este es el caso del ejemplo seleccionado que muestra un fenómeno bastante frecuente en ciencia, en el cual los científicos se valen -en términos de Lingüística- de distintas vías genéricas para presentar sus investigaciones que, por centrarse en el mismo objeto de estudio, pueden llegar a tener el mismo título como los ejemplos seleccionados. Por tanto, en la lengua de partida y en la lengua de llegada, ayuda la solución propuesta por Alcano de incluir no el nombre del autor, porque como vimos, es también el mismo, sino otros rasgos distintivos como, por ejemplo, la fuente a través de la que se hizo efectiva la contribución o el tipo de contribución hecha por el autor, es decir, si es una publicación, una conferencia, un póster, etc. En efecto, así se encontró presentado el ejemplo seleccionado:

- Barrantes, F.J. (1991). Structural and functional crosstalk between acetylcholine receptor and its membrane environment. XIVth International Congress of Biochemistry, Jerusalen, Israel, agosto 4-8.

- Barrantes, F.J. (1992). Structural and functional crosstalk between the acetylcholine receptor and its membrane environment. Molecular Neurobiology, 6:463-482.

- Barrantes, F.J. (1992). Structural-functional crosstalk between the nicotinic acetylcholine receptor and its membrane environment. Conferencia en International Workshop on Structure-function relationships of membrane proteins: An assessment of current knowledge, Jarandilla de la Vera, Cáceres, España - octubre.

En cuanto a la función referencial de los títulos científicos altamente especializados, rige el principio según el cual estos deben indicar el contenido que trata el artículo del cual ellos son parte. Curiosamente, la realidad en ciencia parece indicar que esta es una verdad que no siempre se cumple y que preocupa a la comunidad científica (Imbelloni, 2012; Brenner, 1998). De aquí surgen problemas de diferente naturaleza de los cuales, por razones de espacio, vamos a considerar solamente dos en estrecha relación con la traducción de títulos científicos altamente especializados del inglés al español o viceversa. 
Un problema está relacionado con la corrección y precisión terminológica en la lengua de partida y en la lengua de llegada, problema que puede ser tal para: i) el traductor que no es científico; ii) el traductor que es científico de la especialidad; e iii) el científico de la especialidad que no es traductor. Para estos tres posibles agentes intervinientes, corrección y precisión podrían ser lo mismo, aunque, en verdad, no lo son ya que mientras la precisión busca la máxima aproximación semántica, la corrección busca la eliminación de todo defecto/error que conduzca a la redacción lo más correcta posible. Si bien ambas condiciones exigen tratamiento cuidadoso por parte del traductor independientemente de que su situación sea i), ii) o iii), es probable que la precisión sea menos problemática que la corrección, máxime cuando la traducción es para una comunidad de pares. Por el contrario, para alcanzar corrección linguística, además de precisión, condición esta que domina el científico, se requieren otras condiciones que no pasan estrictamente por el conocimiento que se tenga del objeto de estudio. Más aun, la condición de precisión en la traducción puede hacerse efectiva directamente y exclusivamente con la asistencia del científico de la especialidad si el traductor no lo es, y si faltase precisión en la lengua de partida o en la lengua de llegada, hecho que se consideraría error, esto no necesariamente sería obstáculo para la comprensión apropiada del título porque la comunidad de pares puede salvar convenientemente este problema. Por el contrario, si faltase corrección en la lengua de partida o en la lengua de llegada, en dicho caso estamos frente a un defecto que podría conducir a una interpretación no apropiada del título, y en consecuencia, a una traducción incorrecta. Consideremos el siguiente ejemplo extraído de investigaciones anteriores (Soler, 2005, 2011b):

- Autocrine epidermal growth factor signaling stimulates directionally persistent mammary epithelial cell migration - publicado en Journal of Cell Biology 155:1123-1128, 2001.

Para el traductor en cualquiera de las condiciones anteriormente señaladas (i, ii o iii), el ejemplo no presenta problemas de precisión terminológica y si los presentara, particularmente para el traductor en la situación i), acabamos de decir que quienes forman la comunidad de pares del autor o el propio autor son claves en la solución del problema. Ahora bien, ise puede hablar de corrección en la formulación del título? Curiosamente si no hubiese sido por el ejercicio de traducir dicho título del inglés al español (Soler, 2011b), no hubiera sido posible advertir que este título no está correctamente formulado en la lengua de partida. En efecto, el problema radica en el hecho de que no se puede ver con claridad si el término 
directionally funciona como adverbio, en cuyo caso modifica al verbo stimulates, o si funciona como modificador del grupo nominal cuyo núcleo es el término migration.

La estrategia a seguir para garantizar una traducción correcta del ejemplo seleccionado, es centrar la búsqueda de información sobre aquellos términos que entendemos son claves en base a los siguientes parámetros: significado (parámetro I), frecuencia de uso según variables disciplinares (parámetro II) y colocaciones frecuentes (parámetro III). El significado es un parámetro obligatorio a pesar de que la intuición puede tentar al traductor a no buscar o a no corroborar este parámetro en la literatura específica. El parámetro II permite ver en qué campos disciplinares el término clave tiene un regimen de uso regular, lo cual permite delimitar su campo semántico. Este último ayuda, a su vez, a identificar en qué colocaciones (Koike, 2001) el término clave aparece con más frecuencia y a partir de las cuales es posible orientar la búsqueda de información estrechamente relacionada con el uso del término que nos interesa en la disciplina específica en la que ha sido empleado.

Así, y dado que el término conflictivo es directionally y no puede concluirse -según se dijo- si funciona como adverbio o como modificador del grupo nominal cuyo núcleo es migration, entendemos que precisamente estos dos términos son puntos de partida claves para orientar la búsqueda de información que asegurará una decodificación apropiada del título seleccionado. De este modo, el término directionally (adverbio) nos llevará a centrar nuestra búsqueda de información sobre el sustantivo directional, término que significa (parámetro I) «cualidad de direccional», es decir, cualidad que permite mostrar la orientación de la dirección hacia la cual se orienta algo. El parámetro II indica que este término tiene alta frecuencia de uso en campos disciplinarios muy heterogéneos, entre ellos, energía sísmica (Gama García, Gomez Bernal \& Aguirre Gonzalez, 2010), educación (Ellsworth, 2005), traducción (Pym, 2011), psicología (Espino \& Hernández, 2009), dinámica de la ecología y evolución de las especies (Carroll, Hendry, Resnick \& Fox, 2007), biología (Martin \& Lloyd 2005), etc. Por otro lado, es interesante observar que cuanto mayor es la aproximación al campo disciplinar que registra alta -si no la más alta- frecuencia de uso del término que nos ocupa, mayor es la certeza de las colocaciones en las que aparecerá dicho término. Así, del abanico de campos disciplinares surge que la Biología y la Medicina registran las mayores frecuencias de uso del término que nos interesa, conclusión basada -en esta instancia- en la observación empírica. Este hallazgo que parece ser obvio por el tema que describe el título seleccionado, nos permite concluir que la palabra rectora en nuestra búsqueda debe ser migration que funciona como núcleo del grupo nominal persistent mammary epithelial cell migration y no, el término directionally. 
¿Por qué decimos esto? Porque, tras haber identificado el campo disciplinar que registra la frecuencia más alta de uso del término directionally, encontramos que este término tiene una frecuencia de uso muy baja y que el término que sí registra muy alta frecuencia de uso es directional en colocación precisamente con migration. En efecto, según la herramienta SCIRUS la colocación directional migration [adjetivo + sust./núcleo] registra un índice de frecuencia de 11.098 colocaciones de las que seleccionamos solo algunos ejemplos: directional migration of neurons in the adult brain, directional migration of endothelial cells, is critical for cell directional migration, directional migration of lenkocytes, neuroblast directional migration, favors directional migration and invasiveness of carcinoma cells in vitro, defective directional migration of neutrophils. De estos ejemplos se deduce que la migración es un proceso de movimiento en una dirección determinada, deducción que confirman Vanhoecke, Bracke, Kloosterboer y Depypere (2006, p. 2) en estos términos: «la migración direccional es un prerrequisito para que las células tumorales puedan invadir un tejido» (traducción del autor), y que también confirma nuestra consulta con el científico de la especialidad (Antollini 2005) quien señala que las migraciones celulares son persistentemente direccionales.

Vemos entonces que la colocación directional [premodificador] migration [núcleo] muestra este concepto e indica, por tanto, que los modificadores del grupo nominal en cuestión no debieran llevar el orden de los constituyentes con el que fue publicado originalmente sino que debiera decir: Autocrine epidermal growth factor signaling stimulates persistently directional mammary epithelial cell migration [La señalización del factor de crecimiento autocrino epidérmico estimula la migración persistentemente direccional de células epiteliales mamarias. Traducción del autor].

Otro fenómeno interesante en relación con las condiciones de precisión y corrección que garantizan el cumplimiento de la función descriptivo/referencial y expresiva, se produce cuando la corrección prima sobre la precisión pero la afecta de modo de que esta no alcanza a realizarse con claridad. En otros términos, si consideramos el siguiente título en el que se perciben claramente las funciones denominativo-distintiva, referencial y expresiva:

- Furland, N.E., Oresti, G.M., Antollini, S.S., Venturino, A., Maldonado, E.N. y Aveldaño, M.I. (2007). Very long chain polyunsaturated fatty acids are the major acyl groups of sphingomyelins and ceramides in the bead of mammalian spermatozoa. Journal of Biological Chemistry, 282:18151-18161.

advertimos que evidencia corrección en el plano del léxico, de la gramática, de la sintaxis, y de la construcción estructural. Sin embargo, a la hora de traducir dicho 
título al español observamos que esta condición de corrección que prevalece en los planos señalados no garantiza precisión, particularmente en el caso del adjetivo major cuyo uso gramatical, si bien es correcto, no determina con límites precisos el alcance semántico del término. Por tanto, hay corrección pero no hay precisión. Surge entonces el interrogante: ¿qué quiere decir major? ¿El más importante, el más numeroso o el más grande de tamaño? Paralelamente, si hacemos una traducción literal de dicho término, vemos que «mayor», término que podría ser su equivalente en la lengua de llegada, significa «que excede a una cosa en cantidad o calidad, de mucha importancia, dícese de la persona que excede en edad a otra» (Diccionario de la Real Academia Española). Vemos entonces que en la lengua española tampoco queda claro si los autores se refieren a los grupos acilos más importantes, más grandes o más numerosos de esfingomielinas y ceramidas. La traducción de este título en particular no será un problema para el traductor ii) e iii) pero sí lo será para el traductor i). En este último caso, y por tratarse, como dijimos, de un discurso horizontal, la consulta al científico (Oresti 2013) permite aclarar que major indica importancia cuantitativa y que, los autores se refieren entonces a las esfingomielinas y ceramidas más importantes numéricamente o, en términos de Oresti, a las más numerosas.

\section{CONCLUSIONES}

Si retomamos los ejemplos que abren el presente trabajo, podemos concluir que: 1) si forman parte de un curriculum vitae en el sector geográfico determinado para este trabajo, no se traducen excepto en los casos en que el encargo de traducción requiera una traducción pública. 2) Si el traductor no es científico, deberá leer el artículo en su totalidad particularmente en el caso de los títulos metafóricos y confirmar con el científico que el título sea también efectivo metafóricamente en la lengua de llegada. 3) Si quien hace la traducción es científico pero no es traductor, debe corroborar que se cumpla el principio de corrección analizado en este trabajo, particularmente en el último título (no known coronary artery disease).

Sorprende concluir que brevedad textual no es sinónimo de simplificación del trabajo de traducción. En efecto, este trabajo ha intentado mostrar el laberinto al que se ingresa a la hora de traducir estas minúsculas unidades textuales que son los títulos científicos altamente especializados, y del cual a veces no es posible salir con traducciones apropiadas porque no responden a uno, alguno o a ninguno de los parámetros claves del encargo de traducción. Por otro lado, en ausencia-según 
antecipamos- de investigación lingüística aplicada sin el sustento de investigación lingüística básica en cuestiones relacionadas con la traducción de títulos científicos altamente especializados en América del Sur, surge el interrogante: ¿qué hacemos?, o mejor aun: ¿́por dónde comenzamos a ordenar el estado de la cuestión?

Sin investigación lingüística básica no habrá direccionalidad en el camino a seguir excepto muestras de casos dispersos en espera de un marco de estudio de referencia. De nuestras reflexiones se desprende que toda investigación lingüística básica que se haga debe incluir un análisis de los parámetros que determinan el encargo de traducción para decidir si deben o no traducirse los títulos científicos, y un análisis de las condiciones de precisión y corrección lingüística que garantizan la efectivización de las funciones de este tipo de títulos. Urge trabajar en esta dirección porque no todo lo que se publica evidencia corrección lingüística. Nuestro primer contacto con un trabajo de investigación podría ser a través de un título con errores que se identifican y reconocen gracias a que se requiere su traducción. Si esta debe hacerse, ien buena hora que la traducción permita identificar y resolver tales problemas! Si esta no debe hacerse, volvemos al principio de este trabajo: los títulos científicos altamente especializados son excelentes ejemplares para programar y llevar a la práctica una didáctica de la traducción. En ambos casos, un estado de la cuestión sobre la traducción de títulos científicos altamente especializados pone orden, recopila lo estudiado sobre el tema y ayuda a marcar el camino a seguir.

\section{$\overline{\text { REFERENCIAS }}$}

ALARCOS, E. (1977). Lenguaje de los titulares. En: F. Lázaro Carreter, L. Michelena Elissalt, R. Escarpit, E. de Bustos, V. de la Serna, E. Alarcos Llorach \& J.L. Cebrian (Eds.), Lenguaje en periodismo escrito (125-147). Madrid: Fundación Juan March.

ANTOLLINI, S. (2005). Comunicación personal.

BAICCHI, A. (2003). Relational complexity of titles and texts: a semiotic taxonomy. En: L. Merlini Barbaresi (Ed.), Complexity in language and text (319-341). Pisa: Edizioni PLUS - Università di Pisa.

BAICCHI, A. (2003). Comunicación personal.

BRENNER, S. (1998). Titles. Current Biology, 8, R1.

BUXTON, A.B. \& MEADOWS, A.J. (1977). The variation in the information content of titles of research papers with time discipline. Journal of Documentation, 33(1), 46-52.

CARROLL, S., HENDRY, A., RESZNICK, D. \& FOX, C. (2007). Evolution on ecological time-scales. Functional Ecology, 21, .387-393.

CHEN, Z. (2004). The comment on translating titles of papers about social sciences. Shanghai Journal of Translators for Science and Technology, 3, 19-20. 
DICCIONARIO DE LA REAL ACADEMIA ESPAÑOLA, http://www.rae.es/drae/, consultado el 4 de enero de 2014.

ELLSWORTH, E. (2005). Posiciones en la enseñanza. Diferencia, pedagogía y el poder de la direccionalidad. Madrid: Ed. Akal.

ESPINO, O. \& HERNANDEZ, E. (2009). Efectos de direccionalidad en condicionales. Psicológica, 30, 40-57.

FORTANET, I., COLL GARCÍA, J.F., PALMER SILVEIRA, J.C. \& POSTEGUILLO, S. (1997). The writing of titles in academic research articles. En: R. Marín Chamorro y Á. Romero Navarrete (Eds.), Lenguas aplicadas a las ciencias y la tecnología: aproximaciones (155-158). Cáceres: Servicio de Publicaciones, Universidad de Extremadura.

FORTANET GOMEZ, I., POSTEGUILlO GOMEZ, S., COLl GARCÍA, J.F. \& PALMER SILVEIRA, J.C. (1998). Linguistic analysis of research article titles: disciplinary variations. En: I. Vázquez Orta \& I. Guillén Galve (Coords.), Perspectivas pragmáticas en linguística aplicada (443-447), Zaragoza: Anubar.

GAMA GARCÍA, A., GOMEZ BERNAL, A. \& AGUIRRE GONZALEZ, J. (2010). Amplificación sísmica en Chilpancingo, Guerrero. Revista Digital Universitaria, 11, 2-14.

GARCÍA YEBRA, V. (2001). Un traductor en constante formación (Entrevista de M. Ibáñez). Revista Mensual del Colegio de Traductores Públicos de la Ciudad de Buenos Aires, 47, 5-7.

GESUATO, S (2008). Encoding of information in titles: Academic practices across four genres in linguistics. En: C. Taylor (Ed.), Ecolingua: the role of e-corpora in translation and language learning (127-157). Trieste: Edizioni Università di Trieste.

GONZALEZ RUIZ, V.M. (2000). La traducción del título cinematográfico como objeto de autocensura: el factor religioso. En: A.B. Lonsdale, D. Ensinger, M. Presas (Eds.) Investigating Translation (161-169). Amsterdam: John Benjamins.

GONZALEZ RUIZ, V.M. (2005). Traducción e ideología en el ámbito de los medios audiovisuales: el caso de los títulos cinematográficos. En: P. Zabalbeascoa Terran, L. Santamaría Guinot \& F. Chaume Varela (Eds.), La traducción audiovisual. Investigación, enseñanza y profesión (127-138). Granada: Comares.

GOODMAN, R.A., THACKER, S.B., SIEGEL, P.Z. (2001). A descriptive study of article titles in peer-reviewed medical journals. Science Editor, 24, 75-78.

GRESS, E. (1976). El arte de traducir. Revista SUR. Problemas de la Traducción, 338-339, 22-35.

HAGGAN, M. (2004). Research paper titles in literature, linguistics and science: dimensions of attractions. Journal of Pragmatics, 36(2), 292-317.

HAMP-LYONS, L. (1987). Study writing: a course in written English for academic and professional purposes. Cambridge: Cambridge University Press.

IMBELLONI, L. (2012). Scientific articles' titles: Thanks for the information contained in your title. Revista Brasilera de Anestesiología, 62, 140.

JOVANOVIC, M. (1990). On translating titles. Babel, 36, 213-222. 
KOIKE, K. (2001). Colocaciones léxicas en el español actual: estudio formal y léxico semántico. Madrid: Universidad de Alcalá de Henares, Servicio de Publicaciones.

LAURENCE, A. (2001). Characteristic features of research article titles in computer science. IEEE Transactions on Professional Communication, 44, 187-194.

MACSHANE, F. (1976). La enseñanza de la traducción. Revista SUR. Problemas de la traducción, 338-339, 22-35.

MARTIN, Z. y LLOYD, D. (2005). Directionality theory: an empirical study of an entropic principle in life-history evolution. Proceedings of the Biological Sciences of the Royal Society, 272, 1185-1194.

MEMORIAS ANUALES DEL INSTITUTO DE INVESTIGACIONES BIOQUÍMICAS DE BAHÍA BLANCA (INIBIBB) correspondientes a 1991 y 1992.

MONSÁLVEZ MÜLLER, A. (1973). Del cumplimiento en Chile de resoluciones pronunciadas por tribunales extranjeros. Santiago: Editorial Andrés Bello.

MOYA, V. (1993). La traducción de títulos y titulares. Letras de Deusto, 33, 159-164.

NAVARRO, F.A. \& BARNES, J. (1996). Traducción de títulos al inglés en Medicina Clínica: calidad e influencia del castellano. Medicina Clínica (Barc), 106, 298-303.

NEGRO ALOUSQUE, I. (2010). La traducción de títulos cinematográficos: ¿Adaptación o creación? En: J.L. Bueno Alonso (Coord.) Analizar datos $>$ Describir variación. (XXVIII Congreso de Asociación Española de Lingüística Aplicada, Vigo, España, 15-17 de abril de 2010, 1091-1104). Vigo: Universidade de Vigo (Servizo de Publicacións).

NEWMARK, P. (1988). Approaches to translation. Cambridge: Cambridge University Press.

NORD, C. (1990). Funcionalismo y lealtad: algunas consideraciones en torno a la traducción de títulos. En: M. Raders \& J. Conesa (Eds.), Libro de Actas de los II Encuentros complutenses en torno a la traducción. (II Encuentros complutenses en torno a la traducción. Madrid, España, 12-16 de diciembre de 1988, 153-162). Madrid: Editorial Complutense.

NORD, C. (2010). Las funciones comunicativas en el proceso de traducción: un modelo cuatrifuncional. Núcleo, 27, 239-255.

ORELLANA, M. (1986): La traducción del inglés al castellano. Guía para el traductor. Santiago de Chile: Editorial Universitaria.

ORESTI, G.M. (2013). Comunicación personal.

PRESIDENCIA DE LA NACIÓN, MINISTERIO DE EDUCACIÓN, República Argentina (2009). Tablas de Equivalencias y Correspondencias de Educación. pp. 248.

PYM, A. (2011). Exploring translation theories. Londres y New York: Routledge.

SCIRUS < http://www.scirus.com>, consultado el 3 de julio de 2013.

SOLER, V. (2005). Lo que nos dicen los títulos científicos especializados. III Coloquio Nacional de Investigadores en Estudios del Discurso. Universidad Nacional del Sur, Bahía Blanca, Argentina, 4-7 agosto. Actas del Congreso (en CD), 1-9. ISBN 978-9871171-62-0.

SOLER, V. (2007a). Writing titles in science: an exploratory study (Research and Discussion Note). English for Specific Purposes - Elsevier 26, 90-102. 
SOLER, V. (2007b). Simbiosis de lo lingüístico y lo no-lingúistico en la formación del traductor científico. Traduçao e Comunicaçao, Revista Brasileira de Tradutores (Brasil) 16, 91 100. ISSN 0101-2789.

SOLER, V. (2009). Títulos científicos en lengua española: Estudio exploratorio. Lebende Sprachen 2, 50-58.

SOLER, V. (2011a). Comparative and contrastive observations on scientific titles written in English and Spanish. English for Specific Purposes 30, 124-137.

SOLER, V. (2011b). Designing ESP material for Spanish speaking scientists: the case of specialized scientific titles under the nominal-group construction in English and in Spanish. ESP Across Cultures 8, 125-138.

SWALES, J. (1990). Genre analysis: English in academic and research settings. New York: Cambridge University Press.

VANHOECKE, B., BRACKE, M., KLOOSTERBOER, H. \& DEPYPERE, H. (2006). Tibolone and its metabolites inhibit invasion of human mammary carcinoma cells in vitro. Maturitas, 54, 229-237.

YAKHONTOVA, T. (2002). Titles of conference presentation abstracts: a cross-cultural perspective. En: E. Ventola, C. Shalom \& S. Thompson (Eds.), The language of conferencing (277-300). Frankfurt am Main: Peter Lang.

Enviado: 5/03/2015

Recebido: 1/04/2015 